\title{
Contribution to the knowledge on Typhlocybinae (Hemiptera, Cicadellidae) in Italy with description of two new species
}

\author{
ADALGISA GUGLIELMINO ${ }^{1}$, FRANCESCO POGGI $^{2} \&$ CHRISTOPH BÜCKLE ${ }^{3}$ \\ 'Dipartimento di Protezione delle Piante, Università della Tuscia, 01100 Viterbo, Italy.E-mail: guglielm@ unitus.it \\ ${ }^{2}$ Via Madonnina 6, I-23873 Missaglia LC, Italy \\ ${ }^{3}$ Neckarhalde 48, D-72070 Tübingen, Germany
}

\begin{abstract}
Variability of populations of the brachypterous Erythria taxa in the northern Apennines and Maritime Alps is investigated, figured and discussed in the context of possible hybridization between E. ferrarii (Puton) and E. alpina (Vidano). Kybos albitalicus sp. nov., a species closely related to $K$. virgator (Ribaut) and living together with this species on Salix alba (L.), and Arboridia itangulata sp. nov., with clear affinity to A. expansa Zachvatkin, are described as new. Several Tamaricella populations from Italy including Sardinia and Sicily, collected on Frankenia laevis L. and Tamarix spp. and provisionally classified as $T$. cf. ribauti (Zachvatkin) are compared in genital morphology, measurements and coloration. Taxonomic problems concerning $T$. ribauti and related species are discussed. The aedeagus and pygofer appendage of Tamaricella gr. cypria (Ribaut) from Pantelleria are figured.
\end{abstract}

Key words: Cicadomorpha, morphology, host plant, hybrid zone, variability

\section{Introduction}

D'Urso (1995a) records for Italy 178 Typhlocybinae species belonging to 41 genera. In subsequent years only about ten further species were added (Alma 1999; D'Urso 1995b; D'Urso \& Guglielmino 1995; Mazzoni \& Lucchi 2002; Guglielmino et al. 2005; Guglielmino \& Bückle 2007; Poggi 1996).

The genus Erythria Fieber is represented in Italy by eight species, two of them, Erythria alpina Vidano and Erythria ferrarii (Puton), brachypterous and distributed only in the northern regions. The genus Kybos Fieber included up to now ten species in Italy, while the genus Arboridia Zachvatkin is represented there by six taxa. For the genus Tamaricella Zachvatkin only T. tamaricis (Puton) and T. gr. cypria (Ribaut) are recorded in Italy.

In this paper initially we figure examples and discuss the variability in the aedeagal morphology of the Erythria species of the ferrarii-alpina complex in the northern Apennines and Maritime Alps. Furthermore, we describe a new Kybos and a new Arboridia species. Finally we discuss taxonomic problems in the genus Tamaricella based on several populations collected on different host plants during the last decades in Italy.

\section{Material and methods}

Samples were obtained on many collecting trips (1993-2009) at several localities on the Italian mainland and Sardinia. The insects were collected using an entomological net and aspirator.

Abbreviations of depositories of the studied material are as follows:

- $\quad$ Muséum Nationale D'Histoire Naturelle, Paris, France (MNHN)

- Dipartimento di Protezione delle Piante, Università della Tuscia, Viterbo, Italy (collection Guglielmino) (CG) 